Sharif University of Technology
Scientia Iranica
SCIENTIA $\quad \begin{gathered}\text { Transactions D: Computer Science E Engineering and Electrical Engineering } \\ \text { http://scientiairanica.sharif.edu }\end{gathered}$

\title{
Investigation of dispersion influence on the chirp microwave generation using microwave photonic link without optical filter
}

\author{
M. Singh ${ }^{\mathrm{a}, *}$ and S. Kumar Raghuwanshi ${ }^{\mathrm{b}}$ \\ a. Department of Electronics \& Communication Engineering, Photonic Research Laboratory (PRL), Indian Institute of Technology, \\ Roorkee 247667, Uttarakhand, India. \\ b. Department of Electronics Engineering, Indian Institute of Technology (Indian School of Mines), Dhanbad 826004, Jharkhand, \\ India.
}

Received 16 February 2016; received in revised form 1 October 2016; accepted 17 December 2016

\author{
KEYWORDS \\ RF photonics; \\ Triple Parallel- \\ Intensity Modulators \\ (TP-IM); \\ Fibre dispersion; \\ RoF; \\ Optical sideband \\ suppression ratio \\ (OPSSR); \\ Radio Frequency \\ Spurious Suppression \\ Ratio (RFSSR).
}

\begin{abstract}
In this work, we investigate the influence of the second-order (2OD) and third-order (3OD) dispersion terms on chirp signal generation and transmission through RF photonic link without any optical filter. Dispersion equations are formalised using Taylor series and Bessel function to study the link performance. Our result (eye diagrams) shows that $2 \mathrm{OD}+3 \mathrm{OD}$ has a significant impact on chirp mm-wave propagation through fibres of different lengths. In this paper, chirp mm signal is controlled at photo detector by individual phase term of external modulators. Moreover, we experimentally demonstrate that the chirp rate can be significantly controlled by properly choosing the type of fibre in the experiments. We discuss the RF photonic link performance in terms of optical sideband suppression ratio (OPSSR), Radio Frequency Spurious Suppression Ratio (RFSSR), and Bit Error Rate (BER). Theoretical results are verified using MATLAB Software.
\end{abstract}

(C) 2018 Sharif University of Technology. All rights reserved.

\section{Introduction}

RF photonics is an excellent technology for modern RoF systems, due to its advantages like reduced size, low cost, large ultra-wide bandwidth, immunity to electromagnetic interference, no electrical-optical conversion, etc. [1-4]. Over the last few decades, RF photonics generation methods such as optical injection locking [5,6], optical phase lock loop [7], and external modulation $[8,9]$ have been reported. Li and Yao successfully demonstrated frequency octupling using two

\footnotetext{
*. Corresponding author.

E-mail addresses: mandeepism@gmail.com and mandeep.singh@manipal.edu (M.Singh)
}

doi: $10.24200 /$ sci.2017.4376 cascaded optical modulators with Optical Sideband Suppression Ratio (OSSR) of $26.79 \mathrm{~dB}$ [8]. Zhang et al. used optical carrier suppression modulation scheme to generate frequency quadrupler scheme with OSSR of $20 \mathrm{~dB}$ [10]. Sextupling optical mm-wave signal with cascaded MZM (both at different transmission points) was obtained with OSSR of $16 \mathrm{~dB}$ [11]. Optical chirp mm-wave generation with external modulation (using cascaded or parallel MZM) has attracted many research groups [8-12]. Shi et al. reported a novel dual-parallel sub-MZM in nested configuration to get sextupling microwave signal with OSSR of $26 \mathrm{~dB}$ [12]. In [13], a dual-parallel MZM configuration was also studied to obtain frequency octupling with OSSR of $17 \mathrm{~dB}$. Moreover, an optical octupling mm-wave with $20 \mathrm{~dB}$ OSSR was proposed using 4-MZMs [14,15]. Recently, Raghuwanshi et al. [16] showed the application of 
chirped arbitrary microwave generation in the field of remote sensing application. In this work, we advocate the impact of Higher-Order Dispersion (HOD) on mmwave traveling through optical fibres of different lengths without any electrical or optical filter.

The work is presented as follows: Section 2 includes the principle of the proposed photonic link (without any electrical or optical filter) along with mathematical formulation of dispersion equation. Details of the experiment are provided in Section 3 . Results are discussed in Section 4. Finally, Section 5 includes conclusion.

\section{Theoretical model}

Figure 1 represents the schematic of the proposed RF photonic link. We have used the Optisystem Software (Version 13) to model our proposed link [17]. An optical carrier (expressed as $E_{0} \cos \omega_{0} t$, where $E_{0}$ and $\omega_{0}$ are the amplitude and angular frequency of the optical carrier, respectively) from a CW laser is injected into Triple Parallel-Intensity Modulators (TP-IMs) (all operating at Maximum Transmission Points (MTP)). The key advantage of using 3-parallel MZM in the proposed link, as compared with cascaded configuration, is more frequency multiplication, improved OSSR, and improved RFSSR. Due to the absence of optical filter in proposed photonic link, the system has more frequency tunability and stability.

The generalized electric field expression at the output of fibre (by adding the transmission phase delay $\left[\beta\left(\omega_{0} \pm 2 n \omega_{\mathrm{RF}}\right) L\right]$ to sidebands $)$ is expressed as [18-22]:

$$
\begin{aligned}
E_{2}(0, t)= & \frac{\alpha}{3} \cdot E_{0}\left\{3 J_{0}(m) e^{j \omega_{o} t+\beta\left(\omega_{0}\right) L}\right. \\
& +J_{2}(m)\left[e^{j\left(\omega_{o} t-2 \omega_{\mathrm{RF}}\right) t+\beta\left(\omega_{o} t-2 \omega_{\mathrm{RF}}\right) L}\right.
\end{aligned}
$$

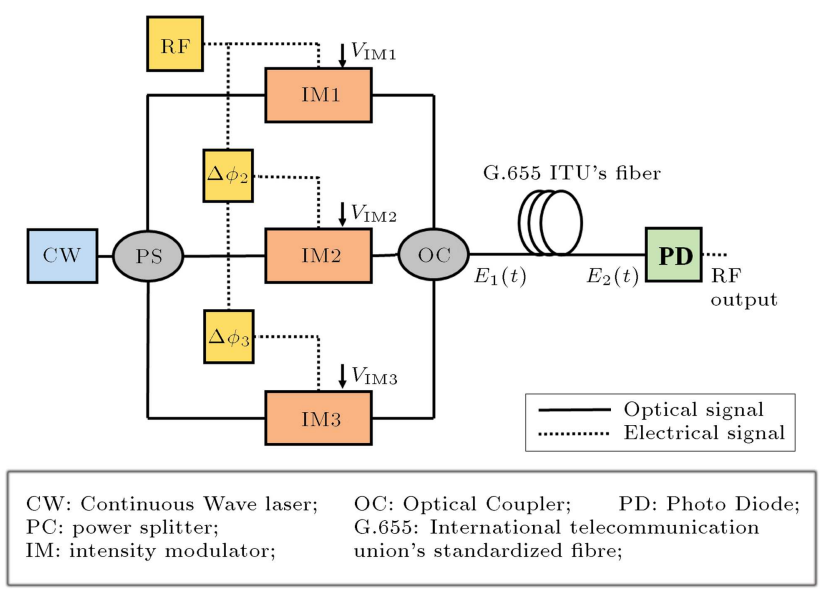

Figure 1. Representative operation of optical chirp mm-wave generation RF photonic link without any optical filter.

$$
\begin{aligned}
& \cdot\left(1+e^{-j 2 \Delta \phi_{2}}+e^{-j 2 \Delta \phi_{3}}\right) \\
& +e^{j\left(\omega_{o} t+2 \omega_{\mathrm{RF}}\right) t+\beta\left(\omega_{o} t+2 \omega_{\mathrm{RF}}\right) L} \\
& \left.\cdot\left(1+e^{j 2 \Delta \phi_{2}}+e^{j 2 \Delta \phi_{3}}\right)\right] \\
& +J_{4}(m)\left[e^{j\left(\omega_{o} t-4 \omega_{\mathrm{RF}}\right) t+\beta\left(\omega_{o} t-4 \omega_{\mathrm{RF}}\right) L}\right. \\
& \cdot\left(1+e^{-j 2 \Delta \phi_{2}}+e^{-j 2 \Delta \phi_{3}}\right) \\
& +e^{j\left(\omega_{o} t+4 \omega_{\mathrm{RF}}\right) t+\beta\left(\omega_{o} t+4 \omega_{\mathrm{RF}}\right) L} \\
& \left.\cdot\left(1+e^{j 2 \Delta \phi_{2}}+e^{j 2 \Delta \phi_{3}}\right)\right] \\
& +J_{6}(m)\left[e^{j\left(\omega_{o} t-6 \omega_{\mathrm{RF}}\right) t+\beta\left(\omega_{o} t-6 \omega_{\mathrm{RF}}\right) L}\right. \\
& \cdot\left(1+e^{-j 2 \Delta \phi_{2}}+e^{-j 2 \Delta \phi_{3}}\right) \\
& +e^{j\left(\omega_{o} t+6 \omega_{\mathrm{RF}}\right) t+\beta\left(\omega_{o} t+6 \omega_{\mathrm{RF}}\right) L} \\
& \left.\cdot\left(1+e^{j 2 \Delta \phi_{2}}+e^{j 2 \Delta \phi_{3}}\right)\right]
\end{aligned}
$$

where $m=\frac{V_{\mathrm{RF}}}{V_{\pi}} \cdot \frac{\pi}{2}$ is modulation depth, $\alpha$ is the optical loss within the IM, $V_{\mathrm{RF}}$ is the amplitude of applied lowfrequency RF signal, and $\omega_{R F}$ is the angular frequency of RF signal. Now, expanding the propagation constant $\beta(\omega)$ for each optical sideband using Taylor series around the angular frequency of the optical carrier [18] as follows:

$$
\begin{aligned}
\beta\left(\omega_{0} \pm 2 n \omega_{\mathrm{RF}}\right)= & \beta\left(\omega_{0}\right)+\frac{d \beta}{d \omega}\left( \pm 2 n \omega_{\mathrm{RF}}\right) \\
& +\frac{1}{2} \frac{d^{2} \beta}{d \omega^{2}}\left( \pm 2 n \omega_{\mathrm{RF}}\right)^{2}+\cdots
\end{aligned}
$$

where:

$$
\begin{aligned}
& \beta_{2}\left(\omega_{0}\right)=\frac{d^{2} \beta}{d \omega^{2}}=2 \mathrm{OD}=\text { group delay dispersion } \\
& \beta_{3}\left(\omega_{0}\right)=\frac{d^{3} \beta}{d \omega^{3}}=3 \mathrm{OD}=\text { dispersion slope }
\end{aligned}
$$

We followed the ITU G.655 fibre manual for dispersion parameter values [23]. In order to suppress the optical carrier, the term " $J_{0}(m) \cdot e^{j \omega_{0} t+\beta\left(\omega_{0}\right) L " ~(i n ~}$ Eq. (1)) must be equal to zero. The output intensity of photodiode (at the end of the fibre, i.e., $z=L$ ) is given by:

$$
I_{\mathrm{PD}}(0, t)=\frac{\alpha}{9} \mu\left|E_{2}(0, t) \cdot E_{2}^{*}(0, t)\right|,
$$

where $\mu$ is the responsivity of the photodiode. 


\section{Experimental setup}

The experiment is set up as shown in Figure 1. An optical carrier with wavelength of $1554.7 \mathrm{~nm}$ is generated from a laser (Yokogawa AQ2200-136) and intensity-modulated via Triple Parallel-Intensity Modulators (TP-IMs). The half voltage of the modulators is $3 \mathrm{~V}$ and $E R$ is above $22 \mathrm{~dB}$. The signals from three IMs are combined by $\mathrm{OC}$ and transmitted over fibres of different lengths (as in Figure 2). The eye diagrams are measured using oscilloscope with a $60-\mathrm{GHz}$ bandwidth. The signal is detected by PD (UTMPDV1120RA) with a $3 \mathrm{~dB}$ cut-off frequency of $30 \mathrm{GHz}$ and responsivity of $0.6 \mathrm{~A} / \mathrm{W}$. Then, the generated electrical signal is analysed by an Electrical Spectrum Analyser (ESA) (FSQ26). The experimentally generated chirped microwave waveform (using Digital Storage Oscilloscope (DSO)) by continuous wave laser is shown in Figure 3.

\section{Results and discussion}

The optical link performance is studied theoretically using both Optisystem Software (Version 13) [17] and MATLAB Software. The simulation model is set up as in Figure 1. Radio Frequency Spurious Suppression Ratio (RFSSR) for fibres of lengths $10 \mathrm{~km}$, $20 \mathrm{~km}, 30 \mathrm{~km}$, and $40 \mathrm{~km}$ is calculated to be $20 \mathrm{~dB}$, $18 \mathrm{~dB}, 17 \mathrm{~dB}$, and $15 \mathrm{~dB}$, respectively (see Figure 4). Moreover, OSSR for the proposed RF photonic link without optical filter is noted to be about $30 \mathrm{~dB}$. The maximum Q-factor from eye pattern for the fibre of length $10 \mathrm{~km}$ under the effect of (a) no dispersion parameter, (b) 2OD, (c) 3OD, and (d) 2OD+3OD is $115.848,86.115,54.3729$, and 30.7302 , respectively

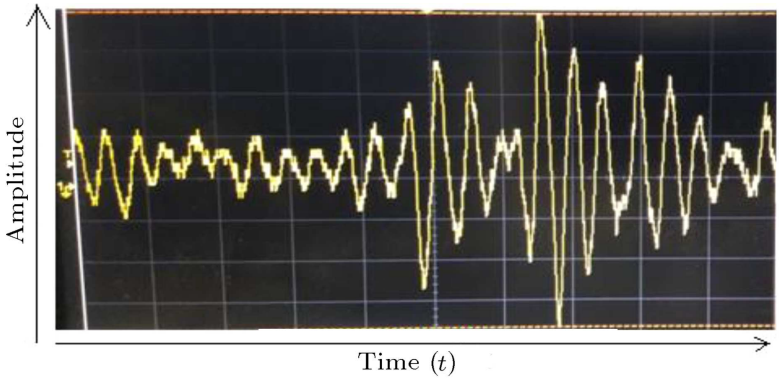

Figure 3. Digital storage oscilloscope (experimental) output of generated chirped microwave waveform due to continuous wave laser. Here, time $(t)$ is in seconds.

(as shown in Figure 5). Also, eye height for the above-mentioned cases is: $2.099 \mathrm{E}-3,1.042 \mathrm{E}-4,5.116 \mathrm{E}-$ 5 , and $1.3633 \mathrm{E}-7$, respectively. Clearly, the eye pattern height is reduced with $2 \mathrm{OD}+3 \mathrm{OD}$, as compared with 2OD. Moreover, simulation shows that BER for $10 \mathrm{~km}$, $20 \mathrm{~km}, 30 \mathrm{~km}$, and $40 \mathrm{~km}$ is nearly $8.24 \mathrm{E}-65,6.12 \mathrm{E}-30$, 0.000824 , and 0.000326 , respectively.

MATLAB results also show that the best performance occurs for $10-\mathrm{km}$ fibre and the worst performance is shown by $40-\mathrm{km}$ fibre (refer to Figure 6 ). The reason for this is that influence of both individual 2OD and 3OD as well as combined 2OD+3OD increases as the fibre length increases.

The influence of $2 \mathrm{OD}, 3 \mathrm{OD}$ and $2 \mathrm{OD}+3 \mathrm{OD}$ is presented in Table 1. Numerical studies (using MATLAB) verified that $3 \mathrm{OD}$ and $2 \mathrm{OD}$ had impact on the optical transmission through the proposed TP-IMs link.

\section{Conclusion}

In summary, this study revealed that Higher-Order

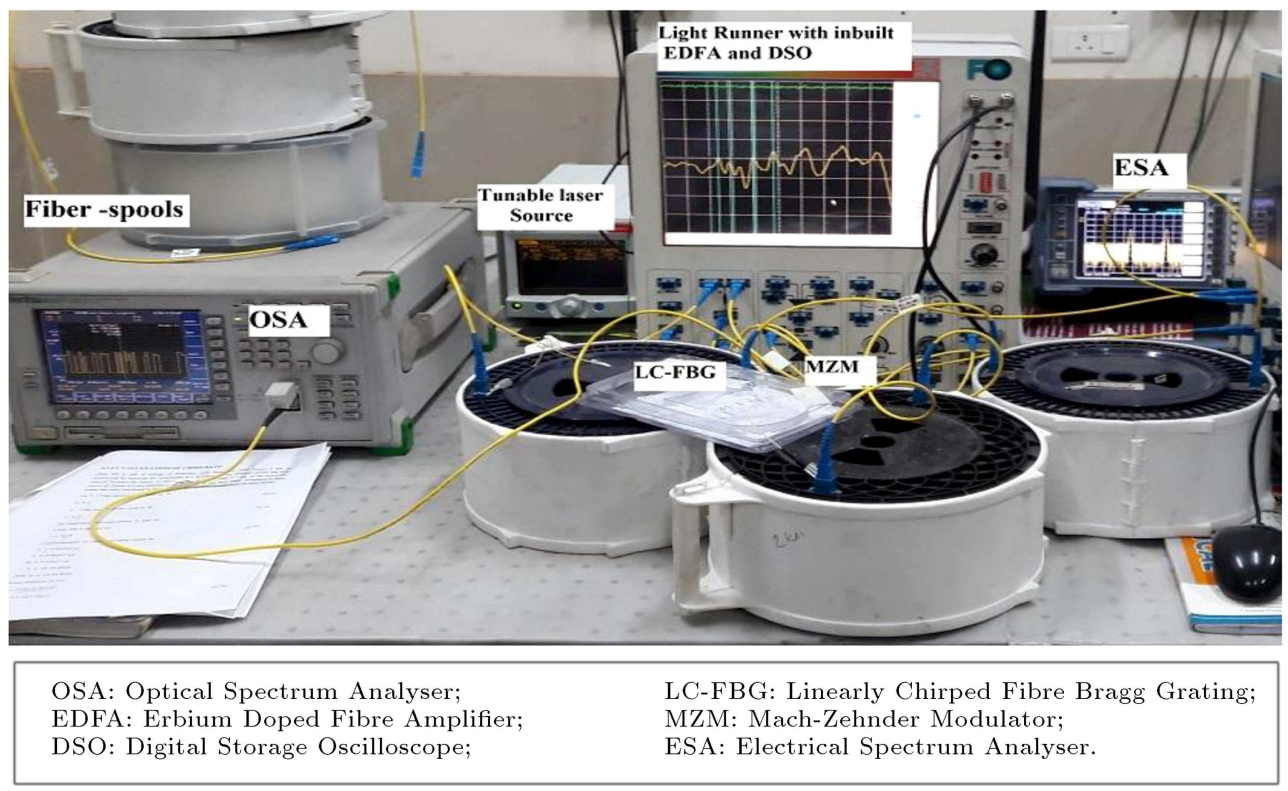

Figure 2. Experimental setup as per proposed model. 


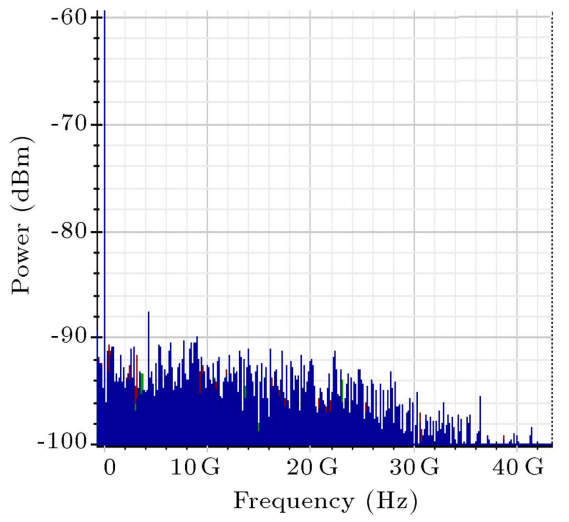

(a)

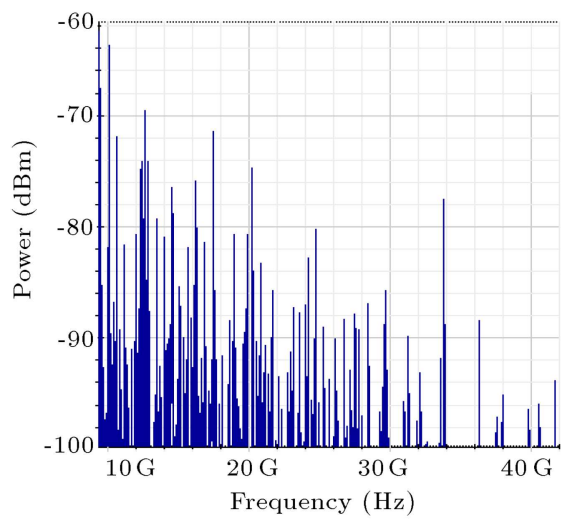

(c)

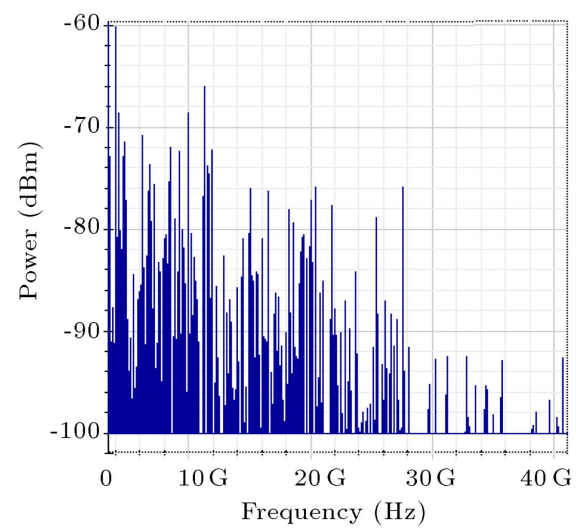

(b)

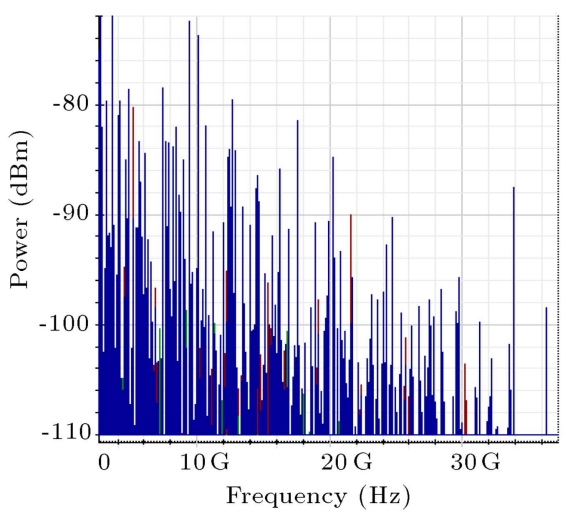

(d)

Figure 4. RF spectrum at the output of photodiode: (a) $10 \mathrm{~km}$, (b) $20 \mathrm{~km}$, (c) $30 \mathrm{~km}$, and (d) $40 \mathrm{~km}$.

Table 1. Summary of the individual and combined dispersion parameters with fibres of different lengths.

\begin{tabular}{|c|c|c|c|c|c|}
\hline \multirow[b]{2}{*}{$\begin{array}{l}\text { Dispersion } \\
\text { order }\end{array}$} & \multirow[b]{2}{*}{$\begin{array}{l}\text { Fibre length } \\
\qquad(\mathrm{km})\end{array}$} & \multicolumn{2}{|c|}{ Experiment } & \multicolumn{2}{|c|}{ Simulation } \\
\hline & & $\begin{array}{c}I_{\mathrm{PD}}(\mathrm{dB}) \\
m=1\end{array}$ & $\begin{array}{c}I_{\mathrm{PD}}(\mathrm{dB}) \\
m=2\end{array}$ & $\begin{array}{c}I_{\mathrm{PD}}(\mathrm{dB}) \\
m=1\end{array}$ & $\begin{array}{c}I_{\mathrm{PD}}(\mathrm{dB}) \\
m=2\end{array}$ \\
\hline \multirow{4}{*}{$\beta_{2}$ only } & 10 & -1.8 & -3.8 & -1.6 & -3.6 \\
\hline & 20 & -2.3 & -4.7 & -2.2 & -4.5 \\
\hline & 30 & -3.2 & -5.8 & -2.9 & -5.6 \\
\hline & 40 & -4.6 & -7.3 & -3.8 & -7.1 \\
\hline \multirow{4}{*}{$\beta_{3}$ only } & 10 & -5.2 & -9.8 & -4.8 & -9.3 \\
\hline & 20 & -6.4 & -14.6 & -6.2 & -14.4 \\
\hline & 30 & -7.2 & -24.6 & -6.9 & -23.5 \\
\hline & 40 & -8.5 & -13.8 & -8.2 & -13.6 \\
\hline \multirow{4}{*}{$\beta_{2}+\beta_{3}$} & 10 & -8.9 & -12.9 & -8.7 & -12.3 \\
\hline & 20 & -9.7 & -11.6 & -9.3 & -11.2 \\
\hline & 30 & -11.2 & -10.1 & -10.9 & -9.7 \\
\hline & 40 & -12.3 & -9.8 & -12.0 & -9.1 \\
\hline
\end{tabular}




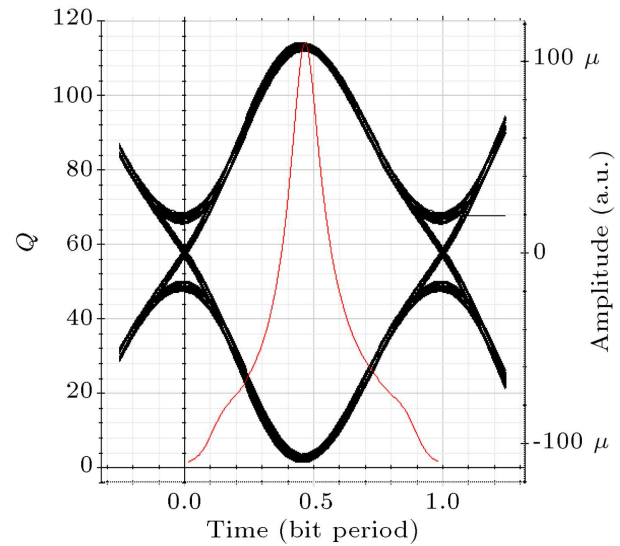

(a)

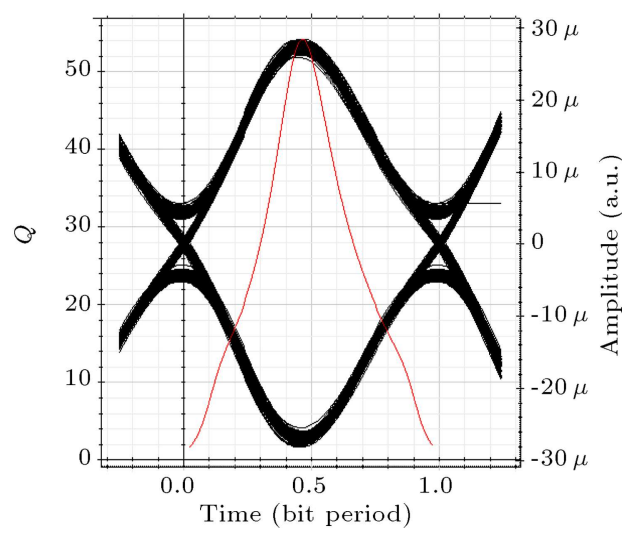

(c)

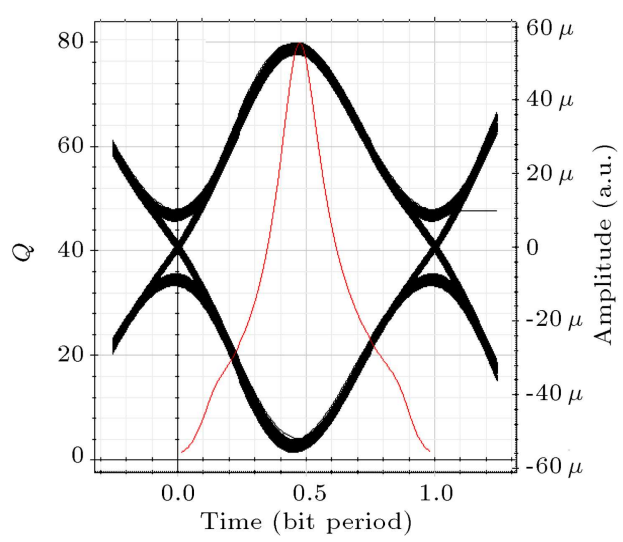

(b)

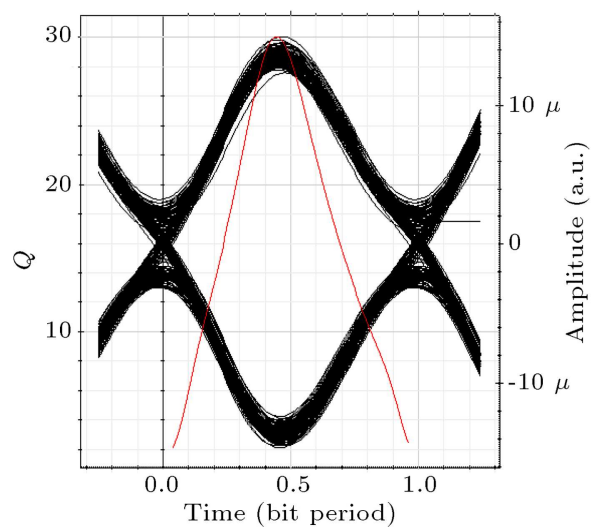

(d)

Figure 5. Eye diagram at the output of photodiode (with 10-km fibre) under the effect of (a) no dispersion parameter, (b) 2OD, (c) 3OD, and (d) 2OD+3OD.

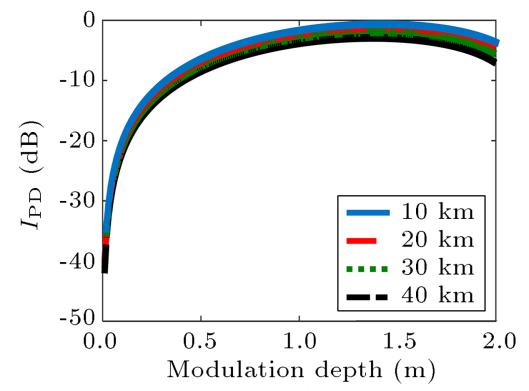

(a)

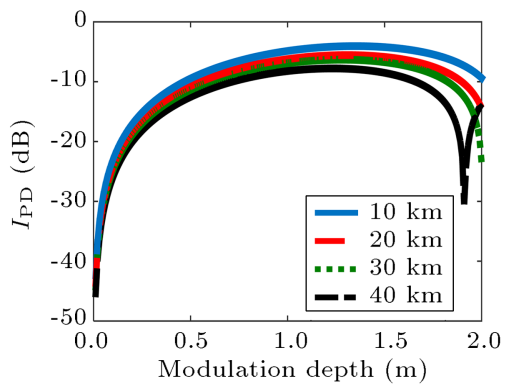

(b)

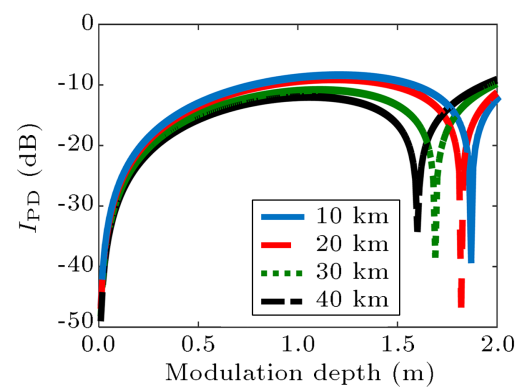

(c)

Figure 6. Plot of intensity at the output of the photodiode versus modulation depth (m) under the effect of (a) 2OD, (b) $3 \mathrm{OD}$, and (c) 2OD+3OD.

Dispersion (HOD) terms had an effect on chirp mmwave generation. The chirp rate could be effectively controlled by selecting the proper type of fibre, viz. Dispersion Compensation Fibre (DCF), Dispersion Shifted Fibre (DSF), Dispersion Flattened Fibre (DFF), etc. We also demonstrated that combined HOD terms [2OD+3OD] had significant effect on $\mathrm{mm}$ wave propagation through fibres of different lengths. For $10-\mathrm{km}$ fibre, RFSSR was $20 \mathrm{~dB}$ and OSSR was nearly $30 \mathrm{~dB}$. Moreover, the proposed Triple Parallel-
Intensity Modulators (TP-IMs) based optical link without optical filter exhibited more frequency tunability and stability.

\section{Acknowledgment}

This work is financially supported by Space Applications Centre, Indian Space Research Organization (SAC-ISRO), Ahemdabad, India with ISRO Respond project entitled "A novel Mach-Zehnder Modulator 
based integrated photonic highly steerable beamforming system for broadband satellite communication link". The work is carried out under Project number: ISRO/(10)/2018-2019/571/ECE (Grant No. DS2B-13012(2)/13/2018). Also, authors would like to thanks Director of IIT (ISM) Dhanbad, SAC-ISRO, Ahmedabad and MIT, Manipal for providing necessary experimental facilities. Authors would also like to thanks reviewers for their useful comments.

\section{References}

1. Yao, J.P. "Microwave photonics: Arbitrary waveform generation", Nature Photonics, 4, pp. 79-80 (2010).

2. Li, W. and Yao, J. "Generation of linearly chirped microwave waveform with an increased time-bandwidth product based on a tunable optoelectronic oscillator and a recirculating phase modulation loop", IEEE J. Lightwave Technol., 32(20), pp. 3573-3579 (2014).

3. Capmany, J. and Novak, D. "Microwave photonics combines two worlds", Nature Photon., 1, pp. 319-330 (2007).

4. Supradeepa, V.R., Long, Ch.M., Wu, R., Ferdous, F., Hamidi, E., Leaird, D.E., and Weiner, A.M. "Combbased radiofrequency photonic filters with rapid tunability and high selectivity", Nature Photonics, 6, pp. 186-194 (2012).

5. Goldberg, L., Taylor, H.F., Weller, J.F., and Bloom, D.M. "Microwave signal generation with injectionlocked laser diodes", IEEE Electron. Lett., 19, pp. 491493 (1983).

6. Jung, T., Shen, J.-L., Tong, D.T.K., Murthy, S., Wu, M.C., Tanbun-Ek, T., Wang, W., Lodenkamper, R., Davis, R., Lembo, L.J. and Brock, J.C. "CW injection locking of a mode-locked semiconductor laser as a local oscillator comb for channelizing broad-band RF signals", IEEE Trans. Microwe. Theory Tech., 47, pp. 1225-1232 (1999).

7. Ramos, T. and Seeds, A.J. "Fast heterodyne optical phase-lock loop using double quantum well laser diodes", IEEE Electron. Lett., 28, p. 1 (1992).

8. Li, W. and Yao, J. "Investigation of photonically assisted microwave frequency multiplication based on external modulation", IEEE Trans. Microw. Theory Techn., 58, pp. 3259-3268 (2010).

9. Gao, Y., Wen, A., Yu, Q., Li, N., Lin, G., Xiang, Sh., and Shang, L. "Microwave generation with photonic frequency sextupling based on cascaded modulators", IEEE Photon. Technol. Lett., 26, pp. 1199-1202 (2014).

10. Zhang, J., Chen, H., Chen, M., Wang, T. and Xie, S. "A photonic microwave frequency quadrupler using two cascaded intensity modulators with repetitious optical carrier suppression", IEEE Photon. Technol. Lett., 19, p. 1057 (2007).

11. Mohamed, M., Zhang, X., Hraimel, B. and Wu, K. "Frequency sixupler for millimeter-wave over fiber systems", Opt. Express, 16, p. 10141 (2008).
12. Shi, P., Yu, S., Li, Z., Song, J., Shen, J., Qiao, Y., and $\mathrm{Gu}, \mathrm{W}$. "A novel frequency sextupling scheme for optical mm-wave generation utilizing an integrated dualparallel Mach-Zehnder modulator", Opt. Commun., 283, p. 3667 (2010)

13. Ma, J., Xin, X., Yu, J., Yu, Ch., Wang, K., Huang, H., and Rao, L. "Optical millimeter wave generated by octupling the frequency of the local oscillator", $J$. Opt. Netw., 7, pp. 837-845 (2008).

14. Guemri, R., Lucarz, F., Bourreau, D., KamfeIt, C., de Bougrenet de la Tocnaye, J.-L., and Hall, T. "Filterless millimetre-wave optical generation using optical phase modulators without DC bias" Proc. IEEE 10th Conf. Ph.D. Res. Microelectron. Electron. (PRIME), pp. 1-4 (2014).

15. Gao, Y., Wen, A., Jiang, W., Liang, D., Liu, W., and Xiang, Sh. "Photonic microwave generation with frequency octupling based on a DP-QPSK modulator", IEEE Photon. Technol. Lett., 27, pp. 2260-2263 (2015).

16. Kumar Raghuwanshi, S., Srivastav, A., and Singh Athokpam, B. "Review on photonic generation of chirp arbitrary microwave waveforms for remote sensing application", Journal of Optical Communications, 38, pp.1-15 (2016).

17. Opti System-user's manual, OPTIWAVE Inc (Version 13).

18. Singh, M. and Kumar Raghuwanshi, S. "Effect of higher order dispersion parameters on optical millimeter-wave generation using three parallel external optical modulators", J. Appl. Phys., 117, p. 023116 (2015).

19. Singh, M. and Raghuwanshi, S.K. "Impact of higher order dispersion on photonically assisted optical millimeter-wave generated using dual parallel electrooptic modulators,", Curr. Appl. Phys., 14(12), pp. 1837-1844 (2014).

20. Singh, M. and Raghuwanshi, S.K. "Microwave generation analysis with higher order dispersion parameters in two cascaded Mach-Zehnder modulators", Opt. Int. J. Light Electron. Opt., 125, pp. 761-771 (2014).

21. Raghuwanshi, S.K. and Singh, M. "Effect of higher order dispersion terms on microwave generation due to single mode fiber, dispersion shifted fiber and nonzero dispersion shifted fiber on lithium niobate machzehnder modulator", Int. J. Electr. Electron. Eng. Res., 3(1), pp. 189-208 (2013).

22. Singh, M. and Kumar Raghuwanshi, S. "Impact of dispersion order on optical millimetre-wave generation based on series optical external modulators without an optical filter", Optica Applicata, 45(2), pp. 215-226 (2015).

23. ITU-T, Rec. G.655, Characteristics of Non Zero Dispersion Shifted Single Mode Optical Fiber Cable, pp. 13-15 (2009). 


\section{Biographies}

Mandeep Singh obtained the BTech degree in Electronics and Communication Engineering from Beant College of Engineering and Technology, Gurdaspur, India, in 2010, and MTech degree in Electronics and Communication Engineering from IIT (ISM) DHAN$\mathrm{BAD}$, INDIA, in 2013. Also, he received his $\mathrm{PhD}$ degree in ECE from IIT Roorkee-INDIA. His area of research is optical fibre communication and plasmonics. $\mathrm{He}$ is doing ISRO project jointly with Dr. Sanjeev Kumar Raghuwanshi, Assistant Professor, Department of Electronics Engineering, IIT (ISM) Dhanbad.

Sanjeev Kumar Raghuwanshi (IEEE M'12) received the BTech degree in Electronic and Instru- mentation Engineering from SGSITS Indore, Madhya Pradesh, India, in 1999, and the MTech degree in Solid State Technology from the Indian Institute of Technology, Kharagpur, in 2002. Moreover, he received the $\mathrm{PhD}$ degree in Optics from the Department of Electrical Communication Engineering, Indian Institute of Science, Bangalore, India. He is an Assistant Professor with the Electronics Engineering Department, Indian Institute of Technology (Indian School of Mines), Dhanbad, India. He is a fellow of the Optical Society of India and a life member of the International Academy of Physics Sciences. He received the Erusmus Mundus Scholarship for his post-doctoral research study with the Instrumentation and Sensor Division, School of Engineering and Mathematical Sciences, City, University of London, UK. 